\title{
Using Personality-Based Propensity as a Guide for Teaching Practice
}

\author{
Lin-Miao L. Agler ${ }^{1, *}$, Kelley Stricklin ${ }^{2} \&$ Larisa K. Alfsen ${ }^{1}$ \\ ${ }^{1}$ School of Psychology, University of Southern Mississippi - Gulf Coast, United States \\ ${ }^{2}$ School of Education, University of Southern Mississippi - Gulf Coast, United States \\ *Correspondence: School of Psychology, University of Southern Mississippi - Gulf Coast, Long Beach, MS 39560, \\ United States. E-mail: lin.agler@usm.edu
}

Received: June 6, 2020

Accepted: July 22, 2020 Online Published: August 17, 2020

doi:10.5430/jct.v9n3p45

URL: https://doi.org/10.5430/jct.v9n3p45

\begin{abstract}
The Big Five-Factor personality traits are examined in the present review. Individual characteristics and personality types may contribute differently to choices of learning strategies and overall cognitive performance. The purpose of this paper is twofold: (1) to provide a brief overview of consistent research findings on personality constructs as predictors of school-related factors, including academic ability, reading and math skills, metacognitive assessments, self-regulatory learning and processing strategies, and students' confidence; and (2) to highlight the applicable value of using personality-related propensities to guide teachers in the classroom. Inter-relationships among personality, cognition, metacognition, self-regulation, and learning outcomes are addressed. More importantly, in the end of the paper, practical teaching and learning applications are discussed and summarized in a table. The table is organized to highlight each personality trait, its significance based on research evidence, and its educational implications for specific teaching methods and strategies teachers can use to draw strengths from each personality trait and to maximize learning in the classroom.
\end{abstract}

Keywords: personality, metacognition, academic achievement, learning strategies, teaching methods

It is well recognized that academic achievement is consistently correlated with cognitive ability, educational attainment, vocational/career success as well as income level (e.g., Deary, 2010; Jensen, 1998; Roberts, Kuncel, Shiner, Caspi, \& Goldberg, 2007). Various individual differences have been found to contribute to academic achievement (e.g., Cheng \& Ickes, 2009), one of which is individual personality characteristics and propensity. Individual differences in personality can exert their influence in general cognitive ability through differences in motivation orientations, learning approaches, confidence levels, achievement goals, and self-regulatory tendency, resulting in different outcomes in academic achievement. A framework of personality that has been consistently used to examine the relationship between personality and academic achievement is the Big Five Model (e.g., O'Connor \& Paunonen, 2007); researchers studying education and personality have shown that this model of personality correlates with different academic outcomes, learning approaches, strategy use, and other school related factors (Jensen, 2015). The purpose of this paper is twofold: (1) to highlight some of the prominent and consistent research findings on the relationship between Big Five personality characteristics and academic-related abilities, including reading and math ability, metacognitive skills in self-regulation and confidence assessments, as well as approaches to learning and processing strategies; and (2) to use personality characteristics as a guide for teaching practice and to offer educational recommendations and practical examples for teachers in the classroom. It is important to emphasize that the authors recognize the difficulty of changing or ameliorating students' aptitudes that are related to stable personality constructs, as demonstrated by the Aptitude by Treatment paradigm (e.g., Cronbach, 1975, Cronbach \& Snow, 1977). Thus, the goal of the teaching recommendations outlined in the present paper is not intended for the purpose of altering students' personality traits. Instead, the personality characteristics are seen as individual propensities that can serve as guiding principles for designing teaching methods that reinforce desirable learning tendency and to create optimal learning outcomes in students. 


\section{Personality}

Personality can be described in terms of a cluster of dimensions that reflect a person's characteristic way to behave, think, and feel (Costa \& McCrae, 1992a, 1992b; McCrae \& Costa, 1997). One of the widely accepted theories of personality is the Five-Factor Model or "Big Five" personality constructs (John \& Srivastava, 1999; McCrae \& Costa, 1997). According to this model, individual differences in behavior, emotion and cognition are described in terms of five broad dimensions: Neuroticism, Extraversion, Openness to Experience or Intellect, Agreeableness, and Conscientiousness. Neurotic people are perceived as emotionally unstable and easily upset. Extraverted individuals are assertive, talkative, and energetic. Openness to Experience or Intellect depicts intellectual, imaginative, and independent-minded individuals. Agreeableness describes good-natured, trustful and cooperative individuals. Those high in Conscientiousness are viewed as responsible, orderly, and dependable (John \& Srivastava, 1999).

\section{Personality, Self-Regulation, and Metacognition}

Research findings have shown significant relationships between aspects of personality and academic achievement, indicating that personality can predict academic performance beyond traditional ability-related measures such as IQ and other cognitive ability tests (Beaujean et al., 2011; Chamorro-Premuzic \& Furnham, 2003a, 2003b; Noftle \& Robins, 2007). It is widely recognized by researchers and educators that one source of influence on academic learning outcome is the ability to self-regulate one's learning. Self-regulation can be defined as learners' beliefs about their ability to choose appropriate actions or behaviors and engage in productive feelings and thoughts in order to achieve their academic and learning goals (Zimmerman \& Schunk, 2001). Thus, self-regulated learning can be conceptualized in terms of setting goals and ensuring completion of these goals through monitoring one's performance and employment of strategies (Bidjerano \& Dai, 2007). The ability to monitor and regulate learning requires effortful control of goals and motivation, which may be influenced by some personality dimensions. Bidjerano and Dai (2007) studied the relationships between self-regulated learning strategies and the Big Five personality traits and found that the former co-varied with the latter, indicating that the tendency to self-regulate one's learning may be rooted in the person's habitual behavioral patterns implicated by the general personality dimensions. Specifically, the researchers found that students high in Consciousness and Openness to Experience (or Intellect) were more likely to use elaboration, critical thinking, and other metacognition skills during learning as well as more likely to regulate their time and effort. It is not surprising that conscientious students, being self-disciplined, deliberate, and hard-working, were better at managing their learning efforts. To make good use of their time, these students also had higher tendencies to locate a quiet place where they could focus on studying. Likewise, it is to be expected that students high in Intellect were more accustomed to evaluate information critically, use metacognitive skills like elaboration, and reflect on their own cognitive functioning while processing information.

Interestingly, when students with low scores on Intellect were considered, Conscientiousness, Agreeableness, and low in Neuroticism (high in emotional stability) mediated the tendency to use time management and effort regulation. In other words, students low in Intellect/Openness to Experience but conscientious, emotionally stable (i.e., low in Neuroticism), and agreeable were more likely to engage in regulation of their time and effort, and such propensity could be a compensatory mechanism for students with lower intellectual potential to handle academic challenges more effectively. According to Bidjerano and Dai (2007), Intellect and effort regulation consistently predicted GPA. As the researchers pointed out, the relationship between Conscientiousness and academic achievement and that between Agreeableness and academic achievement were mediated by self-regulated learning strategies, particularly effort regulation, which is one of the most notable and consistent predictor of academic achievement. Bidjerano \& Dai (2007) called our attention to learners' personality predispositions in acquisition of self-regulatory skills. Certain personality characteristics can facilitate the tendency to employ self-regulated learning strategies or engage in self-regulated learning overall while other personality characteristics may hamper that tendency. However, the researchers emphasized that self-regulated learning behaviors are highly learnable and trainable and that it may be very informative for educators to assess students' personality characteristics to determine who will develop self-regulatory skills more naturally and who might require more explicit training.

The use of self-regulated learning strategies includes the decision to employ different learning approaches to achieve a certain outcome. Previous research evidence has shown that certain personality traits positively correlate with the tendency to use deeper learning approaches (Chamorro-Premuzic \& Furnham, 2009; Swanberg \& Martinsen, 2010) and more effective learning strategies (Bidjerano \& Dai, 2007; Blickle, 1996). Thus, such personality traits are often associated with better learning and performance in school. For example, Chamorro-Premuzic and Furnham (2009) investigated the relationship between five broad personality traits and learning approaches among British and 
American university students. The Neuroticism-Extraversion-Openness-Five-Factor Inventory (NEO-FFI; Costa \& McCrae, 1992) was used to measure personality traits. Students' learning approaches were measured using the Study Process Questionnaire (SPQ; Biggs, 1987). This 42-item inventory measured three categories of learning approaches: surface, deep, and achieving. Surface learning was "a reproduction of what is taught to meet the minimum requirement" (p. 526). Deep learning was defined as "a real understanding of what is learned" (p. 526). Achieving learning referred to approaches aimed to "maximize grade" (p. 526). In each of the three categories, questions were used to inquire about students' learning motives (i.e., "why" questions of learning) and their strategy use (i.e., "how" questions of learning). The results of their study showed that among the five personality traits, Openness to Experience consistently and positively correlated with deep learning motive and strategy. In contrast, Openness to Experience negatively correlated with surface learning motive and strategy and also negatively correlated with achieving learning motive.

Similarly, Swanberg and Martinsen (2010) also investigated the relationships between personality, learning approaches, and academic achievement. Norwegian business students' preferred approaches to learning were assessed using the Norwegian version of the Approaches to Study Skills Inventory for Students validated by Diseth (2001). This 52-item self-reported questionnaire measured surface, deep, and strategic approaches to learning. The surface approach was associated with "unrelated memorizing, lack of purpose, syllabus-boundedness and fear of failure" (p. 79). The deep approach was tied to "meaning-seeking, relating ideas, use of evidence and interest in ideas" (p. 79). The strategic approach was related to "organized studying, time management, monitoring effectiveness, achievement motivation and alertness to assessment demands" (p. 79). The students' personality was assessed using the Norwegian version of the NEO-FFI (Martinsen, Nordvik, \& Østbø, 2003). Academic achievement was determined by a grade on a written exam taken approximately three months after the completion of the learning approach and personality questionnaires. The researchers found that Openness to Experience strongly and positively correlated with the deep approach to learning while Conscientiousness strongly and positively correlated with the strategic approach to learning. On the other hand, Neuroticism was found to strongly and positively relate to the surface approach. Moreover, both Openness to Experience and Conscientiousness were found to be positively correlated with the students' grades on the written exam (Swanberg \& Martinsen, 2010). In sum, the self-regulatory learning patterns and approaches observed in Chamorro-Premuzic and Furnham's (2009) as well as Swanberg and Martinsen's (2010) studies in relation to personality traits, particularly the Openness (Intellect) and Conscientiousness personality traits, were consistent with what was discussed in Bidjerano and Dai (2007). Overall, students with Intellect and Conscientiousness had a higher propensity to utilize deeper information processing strategies, and thus, consistent with the latter study, those personality traits were again shown to be strong predictors of academic achievement in the former two research studies.

\subsection{Recommendations for Teaching Practice}

As Bidjerano \& Dai (2007) pointed out, certain personality traits have the tendency to acquire self-regulatory skills or to use strategic learning more naturally than other personality characteristics. Even though earlier researchers had recognized the difficulty of changing or ameliorating students' aptitudes that are related to personality constructs (e.g., Cronbach, 1975, Cronbach \& Snow, 1977), certain learning behaviors and habits are a lot more malleable and less resistant to change. As the learnable and trainable nature of self-regulated learning behaviors was emphasized (Zimmerman, 1995, 2001), it will be highly valuable for teachers as well as parents to recognize the diverse nature of their learners' ability as a result of an interaction between their propensity and learning approaches. Such interaction can affect components like self-regulation, processing approaches, and strategy utilization. It is widely recognized that an effective teacher is someone who understands and knows her/his students well, someone who is able to foster students' strengths and ameliorate their weaknesses, and someone who can maximize students' learning potential. Therefore, one way to increase teaching effectiveness and thus to maximize positive learning outcomes is to use students' propensity as a guide to determine which students would more likely to develop self-regulatory skills naturally versus those who might require more explicit training.

To summarize research findings from the above section, students who have higher intellect (Openness trait) and conscientiousness tend to be more self-regulated in nature; they are better at utilizing their time and effort effectively for positive learning results and have the propensity to process information strategically in order to extract its meaning compared to learners who are lower in the openness trait, less conscientious, or less emotionally stable or more anxious (high in Neuroticism). At the first glance, one might think that having high intellects (open to new experiences) is the key to be self-regulated and effective learners; however, research in this section showed that the key may lie in other traits than intellects. For example, students with lower intellects (less open to new experiences) can regulate their time and effort well to maximize learning if they tend to be conscientious and agreeable but not 
neurotic. Thus, in the classroom, teachers may avoid singularly focusing on traditionally defined intellectual abilities, as our modern day educational system does. Instead, teachers may see greater educational gains if they devote more instructional resources and energy to fostering a sense of conscientiousness, diligence, and cooperation as well as to build students' emotional stability by setting realistic, achievable goals and thus reducing learners' overall anxiety.

Using a practical example to demonstrate how an English teacher can strengthen the above mentioned traits in students and to foster their tendency to self-regulate, the teacher may implement the method of Reciprocal Teaching (Palincsar \& Brown, 1984) to increase metacognitive regulation and self-awareness of information processing. In Reciprocal Teaching, students learn in a small group atmosphere which encourages cooperation (that is, increasing the agreeable tendency) and discourages a high level of competition that often generates unnecessary anxiety and emotional discomfort (that is, to help reducing the neurotic tendency). The six areas of focus in Reciprocal Teaching are to build background knowledge, predict, clarify unknown or confusing words or phrases, ask questions, summarize, and finally, think metacognitively about which of the areas help the student learn the best. These six strategies encourage students to be open to new experiences and to engage in critical thinking by summarizing, asking questions to clarify confusion, and self-regulating their own learning, all of which strengthens a positive learning outcome and overall intellectual ability. The teacher scaffolds these areas and encourage students to take ownership in each component, which is conducive in building a sense of conscientiousness. The Reciprocal Teaching method has been shown to effectively increase students' reading levels by two grades in just one year regardless of their initial reading ability (Hattie, 2009). Other evidence has also consistently shown that implementing Reciprocal Teaching in the classroom significantly improved students' reading comprehension levels in English as well as other languages (e.g., Navaie, 2018; Oczkus, 2018; Palincsar \& Brown, 1984; Schünemann, Sporer, \& Brunstein, 2013). In addition, this teaching method seemed to be even more beneficial for poor readers; for example, Schünemann et al. (2013) reported that the most growth of fifth graders' reading comprehension as a result of implementing reciprocal teaching strategies along with some self-regulated learning strategies in the classroom was seen in those with the poorest reading skills.

A specific example of reciprocal teaching in action comes from an excerpt in Oczkus's book (2018):

Across town at the high school, 9th graders form discussion circles to dive into the stories of Edgar Allan Poe. They each jot down a quick-write prior to the discussion and then fill in their four door charts in their notebooks as they record their ideas for each of the four reciprocal teaching strategies. Students turn their desks to work in groups of four as they share their brief predictions, questions, words and ideas to clarify, and summaries. They also share a "Why do you think ..." discussion starter and informally run through the reciprocal teaching strategies as they naturally come up in conversation. Students use text evidence in their responses. (p. 139)

\section{Personality and Confidence Judgments}

Research suggests that some of the Big Five personality traits are associated with individuals' confidence judgments of cognitive performance and as a result, would impact their judgment accuracy and reflect their overall metacognitive ability (Buratti, Allwook \& Kleitman, 2013; Dahl, Allwood, Rennemark \& Hagberg. 2010; Schaefer, Williams, Goodie, \& Campbell, 2004). In particular, Extraversion is often found to correlate with overconfidence (Buratti et al., 2013: Dahl et al., 2010; Schaefer et al., 2004). Such overconfidence of extraverts is proposed to be a result of their high confidence that does not match with actual cognitive performance level. The extraverts' abundant confidence is influenced by their nature of being positive in self-esteem and high in optimism (Dahl et al., 2010). In fact, Schaefer et al. (2004) found positive correlations between Extraversion and confidence but no significant correlations between Extraversion and accuracy of actual performance, resulting in extraverts' overconfidence.

Similarly, Openness to Experience shows a consistent positive relationship with confidence judgment (Agler, Noguchi, \& Alfsen, 2019; Buratti et al., 2013; Dahl et al., 2010; Schaefer et al., 2004). Individuals high in Openness to Experience have generally been found to perform better on cognitive tests (Buratti et al., 2013; Dahl et al., 2010). Perhaps due to the tendency to perform better, individuals high in Openness form an elevated sense of confidence. As a result, research evidence has shown significant relations between Openness to Experience and performance confidence (Buratti et al., 2013; Dahl et al., 2010; Schaefer et al., 2004). However, the relationship between Openness to Experience and confidence is not always straightforward. For example, Buratti et al. (2013) found that Openness was related to overconfidence for incorrect but not for correct answers. Even after participants were given a chance to adjust their confidence ratings, they maintained their high confidence level. The overconfidence is likely due to participants giving high confidence ratings across the board without carefully evaluating whether questions were answered correctly or not. The researchers had suggested that such overconfidence in individuals high in 
Openness might be related to their tendency not to doubt their answers due to a deep belief in their intellectual ability/curiosity. To test this assumption, Buratti et al. (2013) further examined the relationship between the Openness to Experience personality trait and the Self Doubt factor. Their results showed a negative correlation between Openness and Self Doubt; that is, individuals indeed are less likely to doubt their own ability if they are high in the Openness trait.

Other relations between the Big Five traits and confidence judgments of cognitive performance have not been consistently demonstrated. Some studies have shown small positive correlations between Conscientiousness and overconfidence (Dahl et al., 2010; Schaefer et al., 2004) and between Agreeableness and overconfidence (Schaefer et al. 2004). However, more studies have not found consistent or significant correlations between Conscientiousness and overconfidence (Agler et al., 2019; Buratti et al., 2013) or between Agreeableness and overconfidence (Agler et al., 2019; Buratti et al., 2013; Dahl et al., 2010). The common characteristics of Conscientiousness and Agreeableness include having a sense of responsibility as well as being dependable, trustful, and cooperative. Thus, the conscientious and agreeable individuals may be more concerned about projecting a realistic sense of confidence instead of an inflated level of confidence because it is a responsible and trustful behavior, and as a result, they may be less likely to be overconfident. In terms of the last Big Five trait, Neuroticism, research findings are not crystal clear. However, although few studies have found Neuroticism negatively but only marginally predicted the level of confidence on older adults' general knowledge (e.g., Dahl et al., 2010), most studies did not find such relationship between Neuroticism and confidence (Agler et al., 2019; Schaefer et al., 2004).

\subsection{Recommendations for Teaching Practice}

Overall, research has demonstrated that individuals who are inclined to be social and out-going as well as those who are more open to new experiences have the tendency to show overconfidence and less self-doubt, which may impair their metacognitive accuracy. Multiple teaching methods can be used to discourage overconfidence and build more accurate cognitive self-assessments in students. First of all, educators can use the idea of Backward Design (Wiggins \& McTighe, 2005) to adjust and mediate the overconfident tendency. Several researchers have demonstrated how to successfully implement Backward Design into science-based curricula (e.g., Hendrickson, 2006; Reynolds, Kearns, $\&$ Dowell, 2017). Backward Design is a method that takes a fully completed task and works backward to develop the details or to identify errors. For example, when students turn in assignments that have errors, the teacher removes the students' names and assigns small groups of students to work backward slowly until they find and correct the errors. A concrete example is a fourth grade science experiment where students built a volcano that erupts. When one group's volcano fails to erupt successfully, they are tasked to go through each step carefully, starting with the last to see where the error(s) are made and then correct them. Working and discussing with peers help students to draw conclusions about common errors they make. When students recognize that the error belongs to them, they may adjust their attitude and adapt self-regulation habits. This method can be particularly useful for students with a high propensity to be indiscriminately overconfident because the back-tracking process encourages them to slow down and to reflect on their work as well as to think through and inspect their learning product more carefully, which in turn can reduce their overconfidence and create a necessary and beneficial level of self-doubt. A degree of self-doubt can help prevent students from being unrealistically confident and help promote the ability to be introspective; as a result, students will be in a better position to produce academic results that are of high quality.

Similar to the Backward/Back-Tracking Design, a second strategy that teachers can use is to place a "Second-Scan Demand" (term coined by the current researchers) on students, which requires students to give a second confidence assessment and to re-evaluate their current understanding of learning. The "second-scan" strategy is to encourage students to give another closer look at their mental processes and to re-assess current understanding to determine if a desirable learning outcome has been achieved. For example, before giving a math test, a teacher can give students 15 minutes to review each concept and re-assess their confidence level on test readiness, and during which time, students can seek clarification and help from the teacher or their peers. This second scan process will allow students to mentally evaluate the current status of their understanding of learning materials and if needed, choose to employ strategies to further their understanding and learning. Related to the second-scan strategy, other researchers have also found the value of slowing students down in the learning process to promote deeper and more meaningful learning. For instance, Pieger, Mengelkamp, \& Bannert (2016) found that reducing fluency is an effective way to counter over-confidence. When reading One Flew Over the Cuckoo's Nest, teachers can slow reading rate down by having a student reread a significant passage aloud, then read the passage again for accuracy, and then read again with more expression, paying attention to prosody.

Finally, another concrete method to steer students away from building unrealistic overconfidence and to help them 
acquire a more responsible, dependable, cooperative, and trustful tendency is to incorporate the Role Rotation strategy (Oczkus, 2018). Teachers can assign roles for each small group member, and rotation of roles is a crucial factor so that all students experience the plethora of roles and the responsibilities that go with each. For example, Open/Intellectual- or Extraverted-leaning students tend to be more accustomed to leading, and when they are assigned a more passive role like gathering materials or information for the group and following instructions from the leader for the commonwealth of the group, it offers those students a different perspective on teamwork and gives them an opportunity to focus less on being a confident leader. On the other hand, allowing an introverted or less intellectual student to take the leader's role gives him/her chances to increase their confidence and be more outspoken and assertive. Oczkus (2018) suggested that teachers rotate multiple reciprocal teaching roles amongst students in small groups, include the roles of Word Watcher (clarifying words or ideas), Predictor (reviewing and predicting based on the material given), Summarizer (making conclusions based on data), Questioner (asking open questions that lead to problem solving), Manager (time watcher and gathering materials), and Leader (making final decisions). An important component of the Role Rotation strategy is using verbal/language communication to build on ideas and understanding. Murphy et al. (2018) has shown that promoting discourse communication among $4^{\text {th }}$ graders led to higher quality discussions and more practical applications of knowledge as well as increasing critical thinking.

\section{Personality, Reading Comprehension, and Other Academic Abilities}

Overall, research evidence indicate that certain Big Five personality traits can influence one's confidence judgments. Most of these studies investigated the relationship between the Big Five personality traits and confidence judgments are in the context of general knowledge and memory recall tasks. Research investigating the effect of the Big Five personality traits on reading comprehension is scarce. If successful reading comprehension involves accurately judging one's understanding during reading (i.e., metacomprehension), one might also expect the Big Five personality traits to be related to reading comprehension ability because some of the traits have been linked to confidence judgments as discussed above. Some evidence has derived from the studies of the role of personality in achievement in English as a foreign or second language (EFL or ESL; see Sadeghi, Kasim, Tan, \& Abdullah, 2012, for a review). There exists a general assumption that individuals high in Extraversion are likely to perform better in a second language compared to less outgoing individuals. However, research does not support this assumption. For example, Bagheri and Faghih (2012) examined the relations between personality type, self-esteem and reading comprehension of Iranian learners of the English language. The Eysenek Personality Questionnaire - short form (EPQ-S)_was used to measure Extraversion dimension of personality, and the Test of English as a Foreign Language (TOEFL) comprehension test was used to measure reading comprehension in English as a Foreign Language (EFL). In line with previous studies, researchers found no significant correlation between Extraversion and reading comprehension. Even though being more sociable and outgoing has been found to have a positive influence on oral performance in EFL (e.g., Bagheri \& Faghih, 2012; Oya, Manalo \& Greenwood, 2004), Extraversion does not seem to have the same effect on reading comprehension.

Recently, Hall et al. (2014) investigated the relationship between reading comprehension of scientific text and personality, as well as cognitive ability and self-efficacy in science. One of the main goals of their study was to examine the influence of scientific text cohesion upon comprehension ability of secondary school children. Text cohesion was defined by the repetition of key terms in high cohesion text and the use of pronouns to refer to key terms in low cohesion text. For example, in the low cohesion text the word 'Enzymes' is referred to by the pronoun 'They' in subsequent sentences (e.g., 'Enzymes have become very important in the industry. They are versatile and far more efficient than other catalysts'; Hall et al., 2014, p. 75). The short version of the Ravens Progressive Matrices (RPM; Raven, Raven, \& Court, 1998) was used to measure participants' general intelligence. Self-efficacy in science was measured using modified Sources of Middle School Mathematics Self-Efficacy (MSMSE) scale (Usher \& Pajares, 2009). The focus of Hall and colleagues' (2014) study was on the Conscientiousness factor of personality. Twelve items from the short five (S5) measure of the Five Factor Model of personality (NEO-PI-R) were used to assess six facets of Conscientiousness (competence, order, dutifulness, achievement-striving, self-discipline, and deliberation). Of these six facets, only dutifulness, which depicts a reliable person who keeps promises, works carefully and thoroughly, and values ethical principles, correlated with comprehension performance. Specifically, low scores on dutifulness in conjunction with low cognitive ability were correlated with poor performance on low cohesion text. Overall, the Conscientiousness dimension of personality as a whole did not show strong association with reading comprehension in this study.

Even though overall research evidence has not established a strong link between the Big Five personality traits with 
reading ability, studies examining the link between the Big Five traits and general cognitive ability and academic success have yielded more clear answers. Conscientiousness has consistently been found to be an important predictor for academic performance, measured by students' Grade Point Average (GPA) (e.g., Kaufman, Agars, \& Lopez-Wagner, 2008; Richardson \& Abraham, 2009). Noftle and Robins' (2007) study revealed some interesting results on personality as a predictor of academic outcomes, measured by GPA and Scholastic Assessment Test (SAT) scores. Consistent with previous findings, Conscientiousness was found to indicate better overall academic performance (GPA), and yet Openness to Experience was significantly related to higher SAT verbal scores. These findings were replicated across four samples using different measures of personality. Among the other dimensions of personality, Extraversion and Agreeableness showed small but inconsistent negative correlations with SAT verbal scores. The researchers further examined facets of each personality trait in relation to SAT scores. All facets of Openness, except Openness to Actions, and only Perfectionism facet of Conscientiousness were positively related to SAT verbal scores. The Flexibility facet of Agreeableness (i.e., willingness to compromise in order to get along with others) negatively related to SAT verbal scores. When examining each individual Big Five traits as a whole, a fairly consistent pattern of relationships emerges, showing that Openness to Experience is the best predictor of SAT scores while Conscientiousness is a stronger predictor for GPAs. In other words, students with high Openness to Experience have higher SAT scores whereas conscientious students are more likely to have better GPAs. However, Noftle and Robin's (2007) study also acknowledged that specific dimensions in each of the Big Five personality traits could demonstrate different degrees of predictive power on academic achievements measured by GPA and SAT. For example, the overall trait, Conscientiousness, failed to predict SAT scores; and yet, after closely investigating different facets of Conscientiousness, the researchers found that the Perfectionism facet of Conscientiousness was positively correlated with SAT verbal scores. In addition, the Flexibility facet of Agreeableness seemed to carry more weight in consistently predicting SAT verbal scores (negative correlation) than the overall, composite Agreeableness trait.

In another study that examined academic achievement predictors, Beaujean et al. (2011) investigated the role of personality and cognitive ability in reading and mathematics achievement in post-secondary students. The American College Testing (ACT) and SAT reading sections with several other reading achievement measures were used to assess academic achievement in reading. The researchers found that Openness to Experience, Conscientiousness and Agreeableness positively related to reading achievement among post-secondary students. On the other hand, Openness to Experience, Conscientiousness, as well as Extraversion were found to predict mathematics achievement. Further analyses taking students' general cognitive abilities into consideration revealed that personality predicted reading achievement independently from students' cognitive abilities. That is, individual differences in personality influenced reading achievement of students with different levels of cognitive abilities. In contrast, for mathematics achievement, Openness to Experience and Extraversion interacted with cognitive abilities in predicting math achievement; specifically, Openness and Extraversion were stronger predictors of math ability for students with lower levels of cognitive abilities. For average and higher ability students, Conscientiousness became insignificant in contributing to math achievement while Openness remained an influential predictor of math achievement. In conclusion, for reading achievement, personality's predictive effects spread across different ability levels. Personality, on the other hand, plays an especially important role in predicting math achievement among lower ability students compared to students of higher cognitive ability.

\subsection{Recommendations for Teaching Practice}

Overall, Conscientiousness and Openness/Intellect are fairly consistent predictors of reading and math abilities when ACT and SAT are examined. Conscientious students also tend to have higher GPAs. The Dutifulness facet in Conscientiousness can be an important predictor for reading ability, especially for students with lower cognitive ability. To promote the propensity of being reliable and dutiful, teachers should assign learners responsibilities with timelines. In reading, an example is to pair students to teach word concepts to each other in order to help each other prepare for an upcoming test; the process of fulfilling one's duty in a timely manner for the success of oneself and the teammate highlights accountability, responsibility, and reliability. In addition, teachers can assign students tasks that require careful and thorough work, which in turn can encourage a sense of dutifulness. For example, a drama teacher may require students to create a theatre script based on the medieval period and then require them to design costumes for the characters in the script. Such assignments would require students to carefully and thoroughly do their research to find out the historical facts related the plot of their script as well as to study the type of fabric and clothing designs for the costumes around that time period.

Finally, the extraversion propensity is found to be positively linked to math performance in students with lower cognitive abilities. One strategy teachers can use to integrate literacy into mathematical concepts and to incorporate 
social and collaborative components to encourage social and verbal communication and thus encourage the extraverted tendency is to use the Word Sort Method (Bear, Invernizzi, Templeton, \& Johnston, 2016). In this method, students are given index cards with mathematical terms or concepts written on them. They work in groups to sort the cards and name the categories of each pile, justifying why they made the sorting choices. For instance, in geometry the terms vertex, intersecting line segments, and chords would be paired together because they all relate to lines. Regardless whether students tend to be more or less outgoing, such verbal communication and social interaction can encourage all students' extraverted tendency, which in turn would benefit their math ability, confidence level, as well as other cognitive ability. In fact, Tierney and Readence (2000) and Thames and Readence (1988) have shown that the use of the Word Sort method improved elementary school age children's reading comprehension, especially those with reading difficulties.

\section{Conclusion}

A primary purpose of this paper was to highlight some of the prominent and consistent research evidence on the relationship between the Big Five personality traits and school related factors, such as academic achievement, cognitive and metacognitive abilities, self-regulatory behaviors, processing approaches, as well as learning motives and strategies. Personality is related not only to cognitive skills and academic performance, but it also correlates with confidence judgments, regulation of learning, and strategy use. Certain personality characteristics have been found to positively correlate with deep approaches to learning, effective learning strategies, and better time/effort management and organizational skills. For example, Openness to Experience and Conscientiousness constructs are associated with better learning and performance because these individuals are more likely to use elaboration, critical thinking, and metacognitive skills. On the other hand, the neurotic tendency has been found to strongly and positively relate with the surface learning approach.

Researchers suggest that the Big Five personality is associated with individuals' levels of confidence judgments of performance and their judgment accuracy. Openness to Experience, in particular, has shown a consistent positive relationship with confidence judgments although the sense of confidence does not reliably match with superior performance. One interesting phenomenon is that students who are Open to Experience tend to maintain their overconfidence even when they have a chance to adjust their confidence judgment. In other words, individuals high in Openness exhibit a tendency not to doubt their answers due to the belief in their own intellectual ability/curiosity.

A second primary purpose of the present paper was to make recommendations using personality-related propensities as a guide for teaching practice and to outline specific teaching strategies that align with such personality tendencies in order to promote optimal learning. Teaching methods and specific examples for classroom teachers were highlighted under each section of the paper to show the connection between personality-based proclivities and specific teaching practice. The authors' goal was to bridge between personality and education research for practical application value with the focus on demonstrating how personality characteristics manifest themselves through specific inclined ways of behaving and thinking, and thus can directly affect multiple academic factors and learning outcomes. More importantly, the authors emphasized that effective teaching methods can help bring out desirable propensities in students to maximize positive learning outcomes. Even though such situational propensities stimulated and encouraged by teachers in the classroom are not equivalent to stable trait-like personality, one cannot deny that any positive learning experiences brought out by such situational stimulation can have a cumulative positive effect on students' overall learning attitude.

Table 1 below is used to summarize the Big Five personality characteristics/tendencies, research significance associated with each tendency, and suggestions for teaching strategies and tips. The outlined teaching methods and examples can be adopted by teachers in their classroom to promote such propensities that are conducive to learning and academic excellence. Future studies are needed to validate the effectiveness of these proposed teaching and instructional strategies in promoting desirable personality propensities in order to maximize positive learning outcomes. Finally, in the past, the Five-Factor of personality has been used by the majority of researchers to examine the influence of personality propensities on academic learning outcome, and there is an extreme scarcity of research evidence gathered using other personality models. Thus, in the future, researchers aiming to gather additional evidence on the academic impacts of individual differences in personality should consider adopting other personality models than the Five-Factor model. 
Table 1. Five Factor Model with Educational Implications and Teaching Strategies and Tips

\begin{tabular}{ll}
\hline $\begin{array}{l}\text { Traits of individuals for Five } \\
\text { Factor Model }\end{array}$ & Significance in Learning \\
\hline $\begin{array}{l}\text { Neuroticism: } \\
\text { Neurotic, emotionally unstable, } \\
\text { easily upset }\end{array}$ & approaches \\
& $\begin{array}{l}\text { 1. Overconfidence, less self-doubt, which } \\
\text { might impair metacognitive ability }\end{array}$ \\
Extraversion: & 2. Not a predictor for reading comprehension \\
bussertive, talkative, energetic predicts better oral performance in & \\
& $\begin{array}{l}\text { learning a foreign language } \\
\text { 3. A predictor for math performance in lower } \\
\text { cognitive ability students (i.e., Students who } \\
\text { have lower cognitive ability but are } \\
\text { extroverted tend to do better in math than } \\
\text { those who are introverted and have lower } \\
\text { cognitive ability.) }\end{array}$
\end{tabular}

Openness to Experiences or 1. Utilize deeper processing strategies such Intellect: as elaboration and critical thinking

Intellectual, imaginative, 2. Incorporate deep learning motive

independent-minded

3. Overconfidence for incorrect answers

4. Less self-doubt, which might impair metacognitive ability

5. Best predictor of SAT scores and a predictor of reading and math performance on ACT and SAT

Agreeableness:

Good-natured, cooperative, trustful, sections cooperative, self-disciplined
Teaching Strategies and Tips

1. Use reciprocal teaching to encourage deep processing (build, predict, clarify, ask, think)

2. Assign rotating roles to establish jobs and routines to reduce emotional instability

1. Use Backward Design, Second Scan Method, and Reading Fluency Reduction Method to lower overconfidence

2. A second language teacher may use the Role Rotation method to strengthen assertiveness and encourage sociability to promote language learning outcome; a math teacher may use the Role Rotation method on lower cognitive ability students in particular to build confidence.

3. Math teachers can use the Word Sort Method to promote social interaction and verbal communication, and thus promote the extraverted tendency which predicts math performance, especially in the lower-ability group.

1. Use Backward Design, Second Scan Method, Reading Fluency Reduction Methods to lower overconfidence

2. Avoid assigning memorization tasks; use problem-based learning that relates concepts and requires a higher level of elaborative processing

1. Assign teaching roles to increase students' sense of responsibility and accountability to promote agreeableness and thus to reduce excessive confidence and to elevate reading ability amongst non-agreeable students 
Conscientious-ness:

Responsible, orderly, dependable, trustful, cooperative,

self-disciplined, able self-regulate, persistent
1. Better at regulating time and effort effectively to produce positive learning outcome

2. Motivated to use strategic learning approaches and utilize deeper processing strategies such as elaboration and critical thinking

3. A consistent predictor for GPA; tend to receive better grades

4. Conscientiousness predicts ACT and SAT reading sections; the dutifulness facet of Conscientiousness is a specific predictor of general reading ability

5. A predictor for math in lower ability students

6. Lower tendency to be overly and inaccurately confident
1. Teach specific self-regulatory strategies including time allotment and effort expenditure to promote responsible and dependable behaviors (Conscientiousness); use reciprocal teaching which encourages engaging in self-regulatory, metacognitive steps

2. Use problem-based learning that requires strategic approaches to encourage creative and critical thinking

3. Use specific praise related to reading behaviors that could improve comprehension

4. Assign roles and responsibilities to raise a sense of dutifulness; assign tasks with timelines and that require careful and thorough work; scaffold responsibilities to strengthen the sense of dutifulness

\section{References}

Agler, L-M. L., Noguchi, K., \& Alfsen, L. K. (2019). Personality traits as predictors of reading comprehension and metacomprehension accuracy. Current Psychology. https://doi.org/10.1007/s12144-019-00439-y

Bagheri, M. S., \& Faghih, M. (2012). The Relationship between self-esteem, personality type and reading comprehension of Iranian EFL students. Theory and Practice in Language Studies, 2(8), 1641-1650. https://doi.10.4304/tpls.2.8.1641-1650

Bear, D., Invernizzi, M., Templeton, S., \& Johnston, F. (2016). Words Their Way: Word Study for Phonics, Vocabulary, and Spelling Instruction (6th ed.). Pearson Education, Inc., Upper Saddle River, N.J.

Beaujean, A. A., Firmin, M. W., Attai, S., Johnson, C. B., Firmin, R. L., \& Mena, K. E. (2011). Using personality and cognitive ability to predict academic achievement in a young adult sample. Personality and Individual Differences, 51, 709-714. https://doi.org/10.1016/j.paid.2011.06.023

Bidjerano, T., \& Dai, D. Y. (2007). The relationship between the big-five model of personality and self-regulated learning strategies. Learning \& Individual Differences, 17(1), 69-81. https://doi.10.1016/j.lindif.2007.02.001

Biggs, J. B. (1987). The Study Process Questionnaire manual. Victoria: Australian Council for Educational Research.

Blickle, G. (1996). Personality traits, learning strategies, and performance. European Journal of Personality, 10(5), 337-352. https://doi.org/10.1002/(SICI)1099-0984(199612)10:5\%3C337::AID-PER258\%3E3.0.CO;2-7

Buratti, S., Allwood, C. M., \& Kleitman, S. (2013). First- and second-order metacognitive judgments of semantic memory reports: The influence of personality traits and cognitive styles. Metacognition Learning, 8, 79-102. https://doi.10.1007/s11409-013-9096-5

Chamorro-Premuzic, T., \& Furnham, A. (2003a). Personality predicts academic performance: Evidence from two longitudinal university samples. Journal of Research in Personality, 37(4), 319-338. https://doi.10.1016/S0092-6566(02)00578-0

Chamorro-Premuzic, T., \& Furnham, A. (2003b). Personality traits and academic examination performance. European Journal of Personality, 17(3), 237-250. https://doi.10.1002/per.473

Chamorro-Premuzic, T., \& Furnham, A. (2009). Mainly Openness: The relationship between the Big Five personality traits and learning approaches. Learning and Individual Differences, 19, 524-529. https://psycnet.apa.org/doi/10.1016/j.lindif.2009.06.004

Cheng, W., \& Ickes, W. (2009). Conscientiousness and self-motivation as mutually compensatory predictors of university-level GPA. Personality and Individual Differences, 47(8), 817-822. 
https://doi.10.1016/j.paid.2009.029

Costa, P. T., Jr., \& McCrae, R. R. (1992a). The NEO PI/NEO-FFI manual. Odessa, FL: Psychological Assessment Resources.

Costa, P. T., Jr., \& McCrae, R. R. (1992b). Revised NEO Personality Inventory (NEO-PI-R) and NEO Five-Factor Inventory (NEO-FFI): Professional manual. Odessa, FL: PsychologicalAssessment Resources.

Cronbach, L. J. (1975). Beyond the two disciplines of scientific psychology. American Psychologist, 30(2), 116-127. https://doi.org/10.1037/h0076829

Cronbach, L. J., \& Snow, R. E. (1977). Aptitude and instructional methods: A handbook for research on interactions. Oxford, England: Irvington.

Dahl, M., Allwood, C. M., Rennemark, M., \& Hagberg, B. (2010). The relation between personality and the realism in confidence judgements in older adults. European Journal of Ageing, 7(4), 283-291. https://doi.10.1007/s10433-010-0164-2

Deary, I. J. (2010). Cognitive epidemiology: Its rise, its current issues, and its challenges. Personality and Individual Differences, 49(4), 337-343. https://doi.10.1016/j.paid.2009.11.012

Diseth, A. (2001). Validation of a Norwegian version of the Approaches to Study Skills Inventory for Students (ASSIST): Application of structural equation modelling. Scandinavian Journal of Educational Research, 45(4), 381-394. https://doi.10.1080/00313830120096789

Hall, S., Basran, J., Paterson, K. B., Kowalski, R., Filik, R., \& Maltby, J. (2014). Individual differences in the effectiveness of text cohesion for science text comprehension. Learning and Individual Differences, 29, 74-80. https://doi.10.1037/t21546-000

Hattie, J. (2009). Visible Learning: a syntheses of over 800 meta-analyses relating to achievement. New York, New York: Routledge.

Hendrickson, S. (2006). Backward approach to inquiry. Science Scope, 29(4), 30-33.

Jensen, A. R. (1998). The g factor: The science of mental ability. Westport, CN: Praeger.

Jensen, M. (2015). Personality traits, learning and academic achievements. Journal of Education and Learning, 4(4), 91-118. https://doi.10.5539/jel.v4n4p91

John, O. P., \& Srivastava, S. (1999). The big five trait taxonomy: History, measurement, and theoretical perspectives. In L. A. Pervin \& O. P. John (Eds.), Handbook of personality: Theory and research (2nd ed.), 102-138. New York: Guilford.

Kaufman, J., Agars, M., \& Lopez-Wagner, M. (2008). The role of personality and motivation in predicting early college academic success in non-traditional students at a Hispanic-serving institution. Learning and Individual Differences, 18, 492-496.

Martinsen, Ø. L., Nordvik, H., \& Østbø, L. E. (2003). Norske versjoner av NEO-PI-R og NEO FFI. Tidsskrift for Norsk Psykologiforening, 42, 421-422.

McCrae, R. R., \& Costa, P. T., Jr. (1997). Personality trait structure as a human universal. American Psychologist, 52, 509-516. https://psycnet.apa.org/doi/10.1037/0003-066X.52.5.509

Murphy, P., Greene, J., Firetto, C., Hendrick, B., Li, M., Montalbano, C., \& Wei, L. (2018). Quality talk: developing students' discourse to promote high-level comprehension. American Educational Research Journal, 55(5), 1113-1160. https://doi.10.3102/0002831218771303

Navaie, L. A. (2018). The effects of reciprocal teaching on reading comprehension of Iranian EFL Learners. Advances in Language and Literary Studies, 9(4), 26-30. http://dx.doi.org/10.7575/aiac.alls.v.9n.4p.26

Noftle, E. E., \& Robins, R. W. (2007). Personality predictors of academic outcomes: Big Five correlates of GPA and SAT scores. Journal of Personality and Social Psychology, 93(1), 116-130. https://doi.10.1037/0022-3514.93.1.116

O'Connor, M. C., \& Paunonen, S. V. (2007). Big Five personality predictors of post-secondary academic performance. Personality and Individual Differences, 43(5), 971-990. https://doi.10.1016/j.paid.2007.03.017

Oszkus, L. (2018). Reciprocal Teaching at Work: Powerful Strategies and Lessons for Improving Reading Comprehension (3rd ed.). Association for Supervision and Curriculum Development. Alexandria, VA. 
Oya, T., Manalo, E., \& Greenwood, J. (2004). The influence of personality and anxiety on the oral performance of Japanese speakers of English. Applied Cognitive Psychology, 18(7), 841-855. https://doi.10.1002/acp.1063

Palincsar, A. S., \& Brown, A. (1984). Reciprocal Teaching of Comprehension-Fostering and Comprehension Monitoring Activities. Cognition and Instruction, 1(2), 117-175. https://doi.org/10.1207/s1532690xci0102_1

Pieger, E., Mengelkamp, C., \& Bannert, M. (2016). Metacognitive judgments and disfluency -Does disfluency lead to more accurate judgments, better control, and better performance? Learning and Instruction, 44, 31-40. https://doi.org/10.1016/j.learninstruc.2016.01.012

Raven, J., Raven, J. C., \& Court, J. H. (1998). Raven manual: Section 1. General overview. Oxford: Oxford Psychologists Press Ltd.

Reynolds, H. L., \& Kearns, K. D. (2017). A planning tool for incorporating backward design, active learning, and authentic assessment in the college classroom. College Teaching, 65(1), 17-27. http://dx.doi.org/10.1080/87567555.2016.1222575

Richardson, M., \& Abraham, C. (2009). Conscientiousness and achievement motivation predict performance. European Journal of Personality, 23, 589-605. https://doi.org/10.1002/per.732

Roberts, B. W., Kuncel, N. R., Shiner, R., Caspi, A., \& Goldberg, L. R. (2007). The power of personality: The comparative validity of personality traits, socioeconomic status, and cognitive ability for predicting important life outcomes. Perspectives on Psychological Science, 2(4), 313-345. https://doi.10.1111/j.1745-6916.2007.00047.x

Sadeghi, N., Kasim, Z. M., Tan, B. H., \& Abdullah, F. S. (2012). Learning styles, personality types and reading comprehension performance. English Language Teaching, 5, 116-123. https://doi.org/10.5539/elt.v5n4p116

Schaefer, P. S., Williams, C. C., Goodie, A. S., \& Campbell, W. K. (2004). Overconfidence and the Big Five. Journal of Research in Personality, 38(5), 473-480. https://doi.10.1016/j.jrp.2003.09.010

Schünemann, N., Sporer, N., \& Brunstein, J. C. (2013). Integrating self-regulation in whole-class reciprocal teaching: A moderator-mediator analysis of incremental effects on fifth graders' reading comprehension. Contemporary Educational Psychology, 38(4), 289-305. https://doi.10.1016/j.cedpsych.2013.06.002

Swanberg, A. B., \& Martinsen, O. L. (2010). Personality, approaches to learning and achievement. Educational Psychology, 30(1), 75-88. https://doi.org/10.1080/01443410903410474

Thames, D. G., \& Readence, J. E. (1988). Effects of differential vocabulary instruction and lesson frameworks on the reading comprehension of primary children. Reading Research and Instruction, 27(2), 1-13. https://doi.org/10.1080/19388078809557930

Tierney, R. J., \& Readence, J. E. (2000). Reading strategies and practices: A compendium (5th ed.). Allyn and Bacon.

Usher, E. L., \& Pajares, F. (2009). Sources of self-efficacy in mathematics: A validation study. Contemporary Educational Psychology, 34, 89-101. https://doi.10.1016/j.cedpsych.2008.09.002

Wiggins, G., \& McTighe, J. (2005). Understanding by Design. Association for Supervision and Curriculum Development. Alexandria, VA. https://doi.10.14483/calj.v19n1.11490

Zimmerman, B. J. (1995). Self-regulation involves more than metacognition: A social cognitive perspective. Educational Psychologist, 30, 217-221. https://doi.org/10.1207/s15326985ep3004_8

Zimmerman, B. J., \& Schunk, D. H. (2001). Self-regulated learning and academic achievement (2nd ed.). Mahwah, MJ: Erlbaum.

\section{Copyrights}

Copyright for this article is retained by the author(s), with first publication rights granted to the journal.

This is an open-access article distributed under the terms and conditions of the Creative Commons Attribution license (http://creativecommons.org/licenses/by/4.0/). 